\title{
Honokiol, a natural biphenyl, inhibits in vitro and in vivo growth of breast cancer through induction of apoptosis and cell cycle arrest
}

\author{
IDO WOLF ${ }^{1,4}$, JAMES O'KELLY ${ }^{1}$, NAOKI WAKIMOTO ${ }^{1}$, ANH NGUYEN ${ }^{1}$, FRANCK AMBLARD ${ }^{3}$, \\ BETH Y. KARLAN ${ }^{2}$, JACK L. ARBISER ${ }^{3}$ and H. PHILLIP KOEFFLER ${ }^{1}$ \\ ${ }^{1}$ Division of Hematology/Oncology, ${ }^{2}$ Women's Cancer Research Institute, Cedars-Sinai Medical Center, \\ UCLA School of Medicine, Los Angeles, CA; ${ }^{3}$ Department of Dermatology, \\ Emory University School of Medicine, Atlanta, GA, USA
}

Received September 11, 2006; Accepted November 24, 2006

\begin{abstract}
Honokiol (HNK), a naturally occurring biphenyl, possesses potent antineoplastic and antiangiogenic properties. We investigated the in vitro and in vivo activity of HNK against breast cancer. HNK exhibited potent anti-proliferative activity against breast cancer cell lines and enhanced the activity of other drugs used for the treatment of breast cancer. In vivo, HNK was highly effective against breast cancer in nude mice. We identified two different effects of HNK on breast cancer cells: cell cycle inhibition, observed at lower doses of $\mathrm{HNK}$, and induction of apoptosis, observed at higher doses of the compound. Our data suggest that HNK is a systemically available, non-toxic inhibitor of breast cancer growth and should be examined for clinical applications.
\end{abstract}

\section{Introduction}

Honokiol (HNK) is a naturally occurring biphenyl which can be extracted from either the root, stem bark or seed cone of several Magnolia species (Fig. 1A) $(1,2)$. HNK has long been known to have antithrombosis, antibacterial and anxiolytic effects (3-6). However, its antitumor activities have only recently been described. In the promyelocytic cell line HL-60, HNK induces differentiation, and shows cytostatic activity (7-9), and in B-cell chronic lymphocytic leukemia (B-CLL) and multiple myeloma, it induces caspase-dependent and -independent apoptosis, enhances cell kill and overcomes resistance to cytotoxic chemotherapy (10-12). HNK was also shown to have potent cytotoxic activities against colon and lung cancers, hepatoma and skin tumors (13-17). Interestingly, HNK has also been shown recently to overcome the multi-

Correspondence to: Dr Ido Wolf, ${ }^{4}$ Present address: Institute of Oncology, Sheba Medical Center, Tel-Hashomer 52621, Israel

E-mail: wolf-i@inter.net.il

Key words: breast cancer, honokiol, apoptosis, cell cycle, epidermal growth factor receptor, p27, p21 drug resistance (MDR) of the breast cancer cell line MCF-7/ ADR (18). HNK is also a potent inhibitor of angiogenesis. It inhibits endothelial proliferation and slows the growth of angiosarcoma (19). These anti-angiogenesis effects are attributed to HNK-induced suppression of vascular endothelial growth factor receptor R2 (KDR) phosphorylation, thus leading to inhibition of the mitogen-activated protein kinase (MAPK) and the phosphatidylinositol 3-kinase (PI3kinase) pathways (19). Additional recognized activities of $\mathrm{HNK}$ include cytochrome $\mathrm{C}$ release and increased cytosolic free calcium (20-22).

Breast cancer is the most common malignant tumor among females, affecting up to one in eight women (23). At diagnosis, approximately $10 \%$ of newly diagnosed breast cancer patients have locally advanced or metastatic disease; and depending on the initial stage, tumor biology, and treatment strategy, $20-85 \%$ of the patients who are diagnosed with early breast cancer will later develop recurrent or metastatic disease (24). Despite major advances in breast cancer treatment, metastatic breast cancer remains essentially incurable, and the median survival time is approximately 2 years. For patients with hormone receptor (HR)-negative or HER2-negative disease and for those who developed endocrine resistance, cytotoxic chemotherapy is the only therapeutic option (24). The discovery of more potent and less toxic therapies for breast cancer is therefore of major importance.

In this study, we report, for the first time, on in vitro and in vivo activity of HNK in breast cancer, and show that these activities are mediated via cell cycle inhibition and induction of apoptosis. Furthermore, we demonstrate that HNK has synergistic activity with histone acetylase inhibitors. Finally, we demonstrate that HNK has activity against HR-negative breast cancer in vivo. These results indicate that HNK is a potential novel therapy for breast cancer.

\section{Materials and methods}

Extraction of pure HNK. HNK was purchased from Conba Pharmaceutical (Zhejiang, P.R. China). HNK was purified to homogeneity by flash chromatography on silica gel (hexane: EtOAc, 85:15) The purified HNK was dissolved in ethanol 
A.

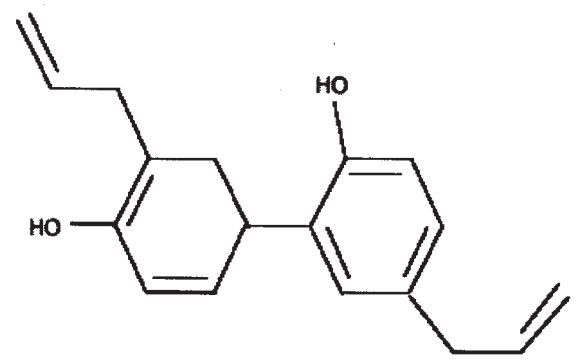

C.

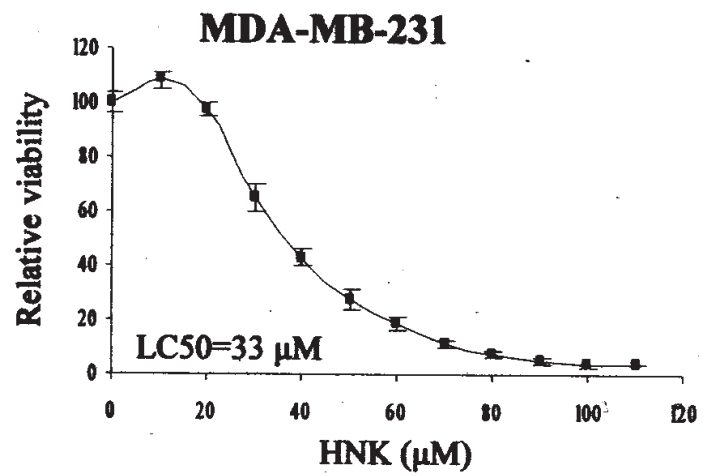

E.

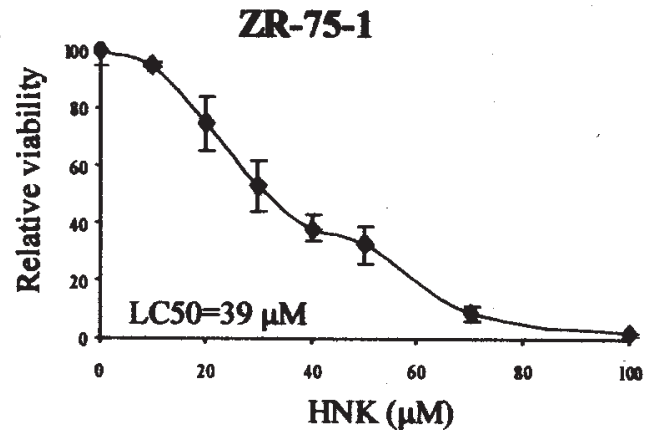

B.

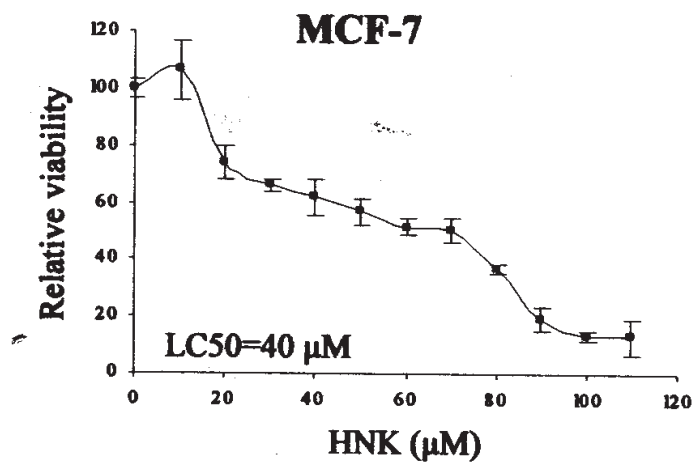

D.

SKBR-3

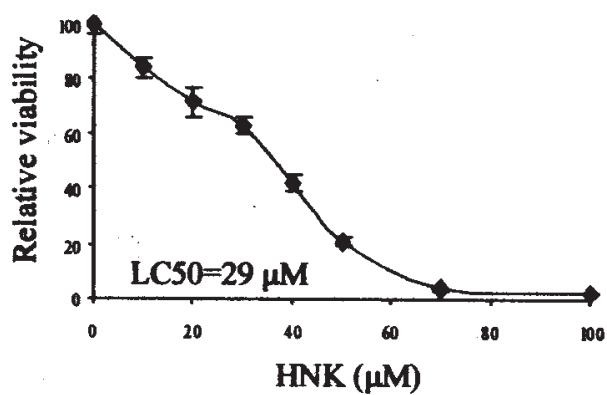

F.

BT-474

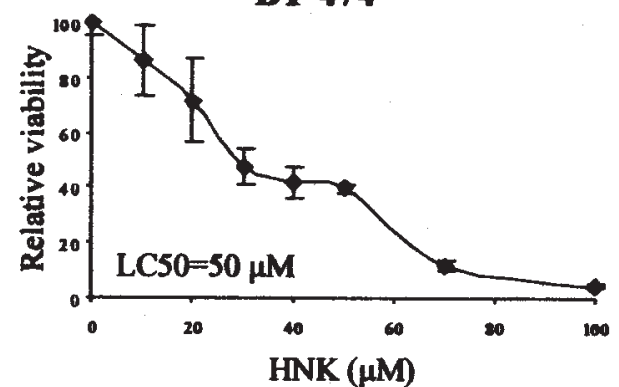

Figure 1. HNK inhibits breast cancer cell proliferation. (A) Schematic representation of HNK structure. (B-F) Breast cancer cell lines were cultured in medium containing the indicated doses of HNK. Viability was measured after $24 \mathrm{~h}$ of treatment, using the MTT assay. Results represent the mean \pm SD of three independent experiments, performed in triplicate. Also shown is the LC50 for each cell line.

to form a stock solution of $75 \mathrm{mM}$, and further dissolved in culture medium to form a working solution at the required concentration.

Chemicals, antibodies and constructs. 4-Hydroxytamoxifen (4-HT, Sigma Chemical Co., St. Louis, MO), doxorubicin hydrochloride $\left(\right.$ Adriamycin $\left.^{\circledR}\right)$, paclitaxel $\left(\right.$ Taxol $\left.^{\circledR}\right)$, and SAHA [kindly provided by Dr V.M. Richon (Merck \& Co., Whitehouse Station, NJ)] were freshly diluted in growth media and immediately added to cells along with HNK, at the indicated concentrations. Cocktail of protease inhibitors (Comp) were obtained from Roche Diagnostic, Alameda, CA. Benzoyloxycarbonyl-Val-Ala-Asp-fluoromethylketone (z-VAD-fmk) (BD Pharmingen, San Diego, CA) was dissolved in DMSO and used at a concentration of $50 \mu \mathrm{M}$. The antibodies used in this study were: anti-p21 (H-164), anti-p27 (C-19), anti-cyclin D1 (H-295), anti-PARP (H-250), anti-BCL-2 (N-19), anti-Bad (K-17) and anti-Bax (N-20), all from Santa Cruz Biotechnology, Santa Cruz, CA; anti-ERK and anti-phospho ERK (BD Transduction Labs, San Jose, CA); anti-caspase 9 (9502), anti-caspase 8 (9746) and anti-caspase 3 (9668) (Cell
Signaling, Danvers, MA); anti-glyceraldehyde-3-phosphate dehydrogenase (GAPDH) (Research Diagnostic Inc., Concord, MA); anti-actin (Cal-biochem Ab-1); horseradish peroxidaseconjugated anti-mouse IgG and anti-rabbit IgG (Amersham Biosciences, Piscataway, NJ); and horseradish peroxidaseconjugated anti-goat (sc-2020, Santa Cruz Biotechnology).

Cell lines. All cell lines were obtained from American Type Culture Collection. The breast cancer cell lines used: MCF-7 and BT-474 cells were grown in DMEM medium containing 10\% FCS; MDA-MB-231, SK-BR-3, MDA-MB-436, ZR-75-1 and T47-D cells were grown in RPMI medium containing $10 \%$ FCS. The glioblastoma multiforme cell lines (U343 and T98G) were maintained in DMEM medium containing $10 \%$ FCS.

Western blot analysis. Cells were harvested and lysed for total protein extraction in a buffer containing $50 \mathrm{mM}$ Tris$\mathrm{HCl} \mathrm{pH} \mathrm{7.4,} 150 \mathrm{mM} \mathrm{NaCl}$ and 2\% NP-40 together with a protease inhibitor cocktail (Comp). Protein extract (50-150 $\mu \mathrm{g}$ ) was loaded on $4-15 \%$ polyacrylamide gels (Bio-Rad, Hercules, 
CA), separated electrophoretically and blotted from the gel onto PVDF membrane. The membranes were then blocked with a blocking buffer (5\% non-fat dry milk in $1 \mathrm{X}$ TBST, i.e. $20 \mathrm{mM}$ Tris- $\mathrm{HCl}, \mathrm{pH} 7.6$ containing $0.8 \% \mathrm{NaCl}$ and $0.1 \%$ Tween-20) at room temperature for $1 \mathrm{~h}$. The membranes were incubated with the primary antibodies in blocking buffer, followed by incubation with HRP-labeled secondary antibodies. Immunoactivity was detected with horseradish peroxidaseconjugated secondary antibody and visualized by enhanced chemiluminescence (Pierce, Rockford, IL). Quantification of the results was performed using Alpha-Imager 2000 (Alpha Innotech, San Leandro, CA).

\section{3-(4,5-Dimethylthiazol-2-yl)-2,5-diphenyltetrazolium} bromide (MTT) proliferation assay. Cells $\left(3 \times 10^{3} /\right.$ well $)$ were plated in 96-well plates, cultured in the appropriate culture media containing $10 \%$ FCS, and treated with either control vehicle or various concentrations of HNK, alone or with a secondary drug, as indicated. All secondary drugs were freshly diluted in growth media and immediately added to cells along with the HNK. After $24 \mathrm{~h}$ of incubation at $37^{\circ} \mathrm{C}, 5 \% \mathrm{CO}_{2}$, the cells were cultured for $4 \mathrm{~h}$ with $10 \%$ MTT reagent ( $5 \mathrm{mg} / \mathrm{ml}$; Sigma-Aldrich, St. Louis, MO). The medium was aspirated, and the cells were dissolved by dimethyl sulfoxide (DMSO). Absorbance of the formazan product was measured by an enzyme-linked immunosorbent assay reader (Macintosh).

Cell cycle assays. For cell cycle assays, $1 \times 10^{6}$ cells were cultured in the appropriate culture media containing $10 \%$ FCS, and treated with either control vehicle or various concentrations of HNK as indicated for $24 \mathrm{~h}$. Following treatment, the cells were harvested, fixed in methanol and stained with propidium iodide (PI, Abcam, Cambridge, MA). Flow cytometry was performed at the Flow Cytometry Core facility of Cedars-Sinai Medical Center, using FACScan (Becton-Dickinson, Franklin Lakes, NJ).

Apoptosis analysis. For apoptosis analysis, $1 \times 10^{6}$ cells were placed in the appropriate culture media containing $10 \%$ FCS, and treated with either control vehicle or various concentrations of HNK for $24 \mathrm{~h}$. Following treatment, cells were harvested, and stained with PI and Annexin V, using the Annexin V-PE Apoptosis Detection Kit I (BD Pharmingen,) according to the manufacturer's protocol. Flow cytometry was performed at the Flow Cytometry Core facility of CedarsSinai Medical Center, using FACScan (Becton-Dickinson). For studies using z-VAD-fmk to inhibit caspase activity, cells were incubated with $50 \mu \mathrm{M}$ z-VAD-fmk for $60 \mathrm{~min}$ prior to addition of HNK.

Animal studies. All animals were maintained and animal experiments were performed under NIH and institutional guidelines established for the Animal Core Facility at the Cedars-Sinai Medical Center. MDA-MB-231 cells were harvested, washed twice with sterile PBS, counted and resuspended in Matrigel (BD Biosciences). Six-week-old female athymic nude mice were injected subcutaneously in both flanks with cells at a density of $1 \times 10^{6}$ viable cells $/ 100 \mu 1$. The mice were treated with daily intra-peritoneal injections
A.

U343

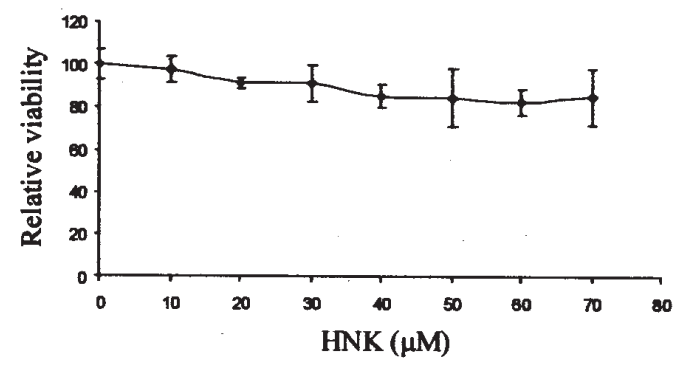

B.

T98G

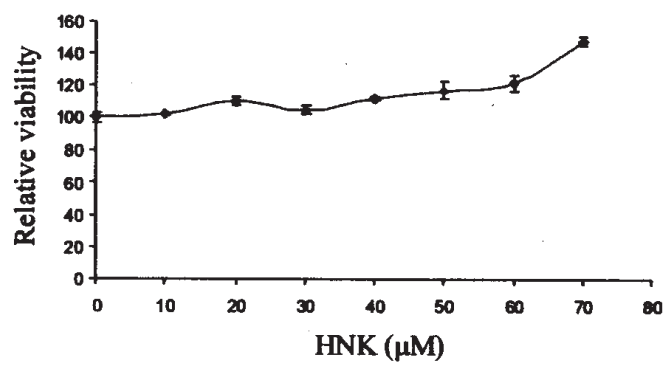

Figure 2. Glioblastoma multiforme cell lines are resistant to HNK treatment. Glioblastoma multiforme cell lines were cultured in medium containing the indicated doses of HNK. Viability was measured after $24 \mathrm{~h}$ of treatment, using the MTT assay. Each experiment was conducted in triplicate and was repeated at least three times.

of either HNK ( $2 \mathrm{mg} /$ day) or vehicle control, suspended in $20 \%$ intralipid (Baxter Healthcare, Deerfield, IL) in a total volume of $0.3 \mathrm{ml}$. Five mice were used in each group. Tumor size was measured with a linear caliper for up to 5 weeks, and the volume was estimated by using the equation $\mathrm{V}=$ $\left(\mathrm{a} \times \mathrm{b}^{2}\right) \times 0.5236$, where ' $\mathrm{a}$ ' is the larger dimension and ' $\mathrm{b}$ ' the perpendicular diameter.

Statistical analysis. Results are presented as mean \pm standard deviation (SD). The study variables were compared between two groups using t-tests. All significance tests were two-tailed and a P-value of $<0.05$ was considered statistically significant. The interaction between two drugs was also analyzed using the additive model. A ratio between the observed and the predicted viability was calculated for all combinations and a ratio $<0.8$ for the interaction was considered to be synergistic $(25,26)$.

\section{Results}

HNK inhibits growth of breast cancer cells. Breast cancer cells were treated with different concentrations of HNK for $24 \mathrm{~h}$, and MTT assays were conducted to assess viability. The selected cell lines have different phenotypes and different expression patterns of the estrogen receptor (ER), HER2 and $\mathrm{p} 53$, and thus represent various subclasses of breast cancer (27). All five cell lines showed dose-dependent reduction in viability in response to HNK (Fig. 1B-F). The concentration that reduced viability by $50 \%$ (LC50) ranged from $50 \mu \mathrm{M}$ for the ER-positive BT-474 cells to $29 \mu \mathrm{M}$ for the poorly differentiated SKBR-3 cell. Similar analyses were 
A.

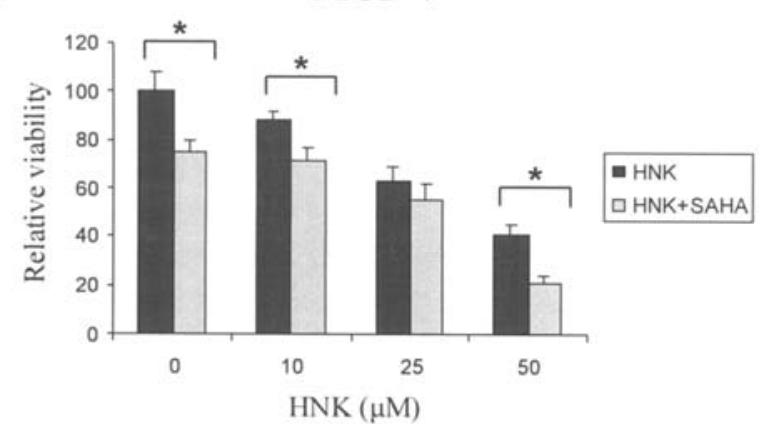

C.

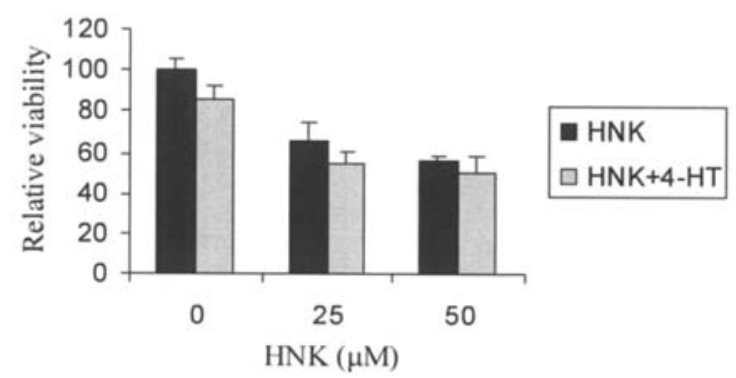

E.

MDA-MB-231

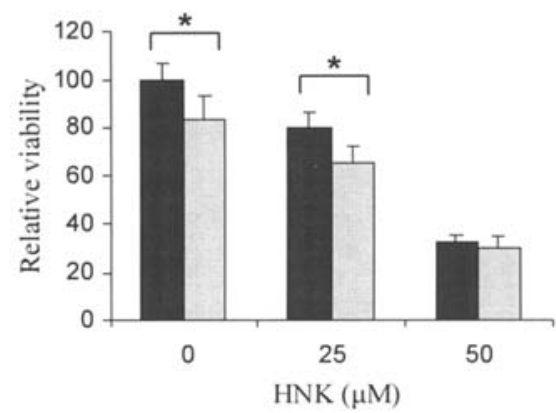

G.

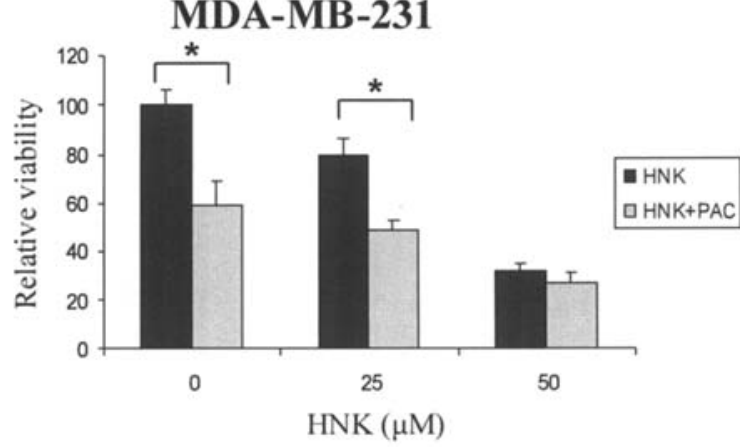

also conducted for two glioblastoma multiforme cell lines, U343 and T98G. Over the same dose-range (10-70 $\mu \mathrm{M})$, both cell lines were resistant to HNK (Fig. 2).

HNK enhances the growth inhibitory activity of other therapeutic agents. We examined the effects of HNK on the antiproliferative activity of 5 drugs with different mechanisms of action against 2 breast cancer cell lines: MCF-7 (ER-positive, wild-type p53) and MDA-MB-231 (ER-negative, mutated $\mathrm{p} 53)$. The cells were treated for $24 \mathrm{~h}$ with various doses of
B. MDA-MB-231

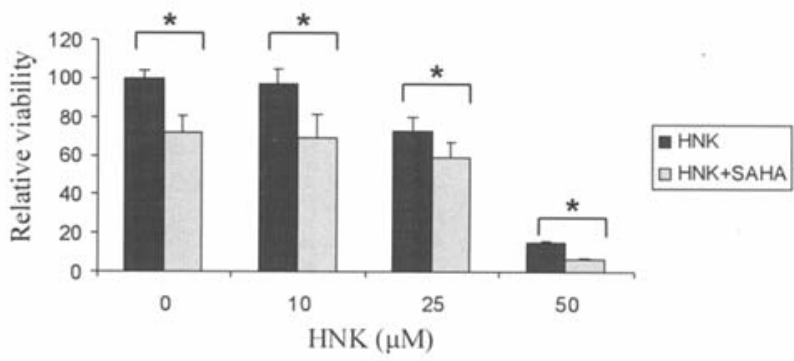

D.

MCF-7

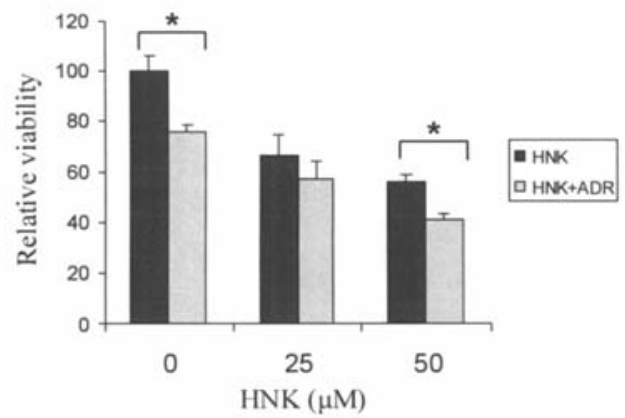

F.

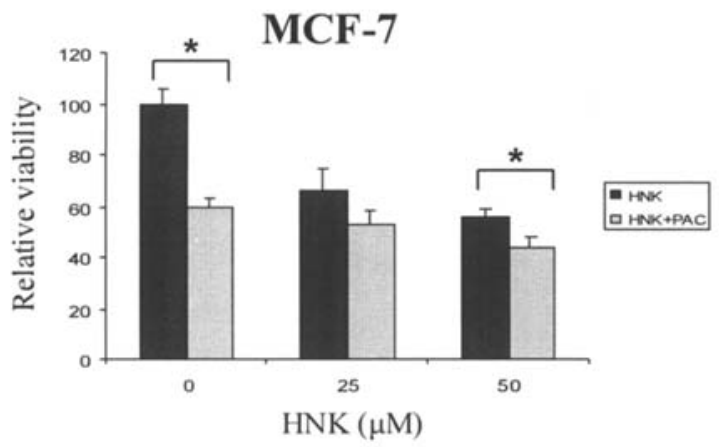

Figure 3. HNK enhances the growth inhibitory activity of other therapeutic agents. MCF-7 and MDA-MB-231 cells were treated with the indicated dose of HNK either alone or in combination with a second drug. Viability was measured after $24 \mathrm{~h}$ of treatment, using the MTT assay. Each experiment was conducted in triplicate and was repeated at least three times, results show the mean $\pm \mathrm{SD} .{ }^{*} \mathrm{P}<0.05$. The secondary drugs used in the study: (A and B) SAHA $(2 \mu \mathrm{M})$; (C) 4-hydroxytamoxifen (4-HT, $100 \mathrm{nM})$; (D and E) doxorubicin (ADR, $300 \mathrm{nM})$; (F and G) paclitaxel (PAC, $250 \mathrm{nM})$.

HNK together with either a control vehicle or a fixed dose of the additional drug; and viability was assessed by the MTT assay. The drugs included: cytotoxic chemotherapeutic drugs (paclitaxel, $250 \mathrm{nM}$; and doxorubicin $300 \mathrm{nM}$ ); 4-hydroxytamoxifen (4-HT, $100 \mathrm{nM}$ ), an inhibitor of the estrogen pathway; and the histone deacetylase inhibitor suberoyl anilide bishydroxamide (SAHA, $2 \mu \mathrm{M}$ ). All these drugs have known activity against breast cancer cells and were used at doses that cause $<50 \%$ growth inhibition (28-31). Significant increased activity was observed for the combinations of HNK and 


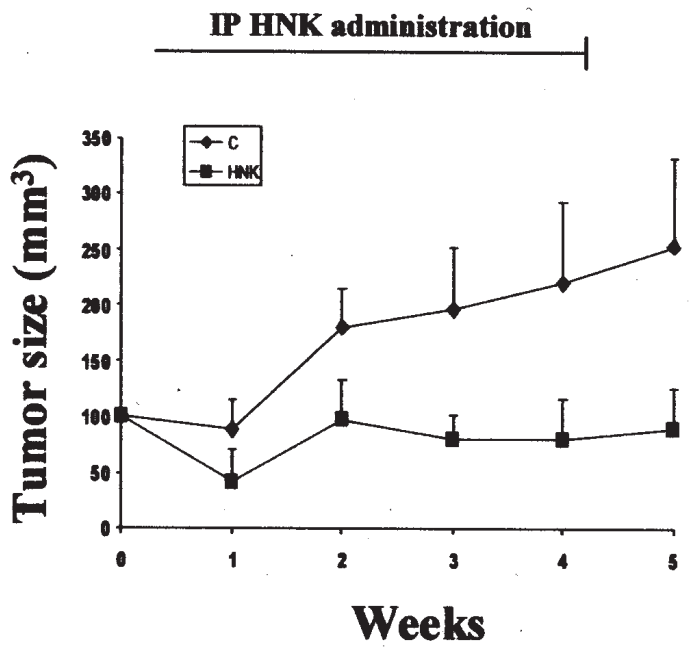

Figure 4. In vivo activity of HNK against breast cancer cells. MDA-MB-231 cells were injected into both flanks of athymic nude mice. The mice were treated with daily i.p. injections of either a vehicle $(\mathrm{n}=5)$ or HNK $(2 \mathrm{mg} / \mathrm{day}$, $\mathrm{n}=5$ ) for 4 weeks. Tumor volume was measured weekly; tumors in the experimental mice were significantly smaller $(\mathrm{P}<0.02)$ by 2 weeks from treatment initiation.

paclitaxel, doxorubicin and SAHA (Fig. 3). Analysis of drug interactions using the additive model identified synergistic interaction for the combination of SAHA and HNK and an additive effect for all other combinations. This synergistic effect of SAHA and HNK was also observed against the SKBR-3, ZR-75 and BT-474 breast cancer cell lines (data not shown).

In vivo activity of HNK against human breast cancer. MDAMB-231 cells were injected on both flanks of nude mice $\left(1 \times 10^{6}\right.$ cells per injection, 5 mice per group, 2 tumors per mouse), and tumor growth was monitored weekly. These cells were chosen based on their ability to easily form tumors in nude mice (27) and their sensitivity to HNK. The mice were treated with daily injections of either $2 \mathrm{mg} \mathrm{HNK}$ $(100 \mathrm{mg} / \mathrm{kg})$ or a control vehicle for 4 weeks; and the tumors were measured weekly. HNK treatment resulted in a complete arrest of tumor growth $(\mathrm{P}<0.02$ from week 2, Fig. 4).

HNK induces apoptosis in breast cancer cell lines. HNK has been shown to induce apoptosis in a wide range of malignant cell types (10-13). We analyzed its ability to induce apoptosis and cell death in breast cancer cell lines. Studies in MCF-7 cells are shown. The cells were treated with HNK $(60 \mu \mathrm{M}$ for 6 or $24 \mathrm{~h}$ ) and apoptosis and cell death were assessed using annexin $\mathrm{V}$ and PI staining (Fig. 5A). After $24 \mathrm{~h}$ of HNK treatment, the number of annexin V-positive, PInegative cells increased significantly, from $1 \pm 0.5 \%$ to $16 \pm 3 \%$ ( $\mathrm{P}<0.05$, Fig. 5B). Western blot analysis revealed degradation of poly(ADP-ribose) polymerase (PARP) and decreased levels of caspase 8 following HNK treatment (Fig. 5C). Upregulation of BAX was also noticed $(85 \%$ increase at $40 \mu \mathrm{M}$ compared
A.

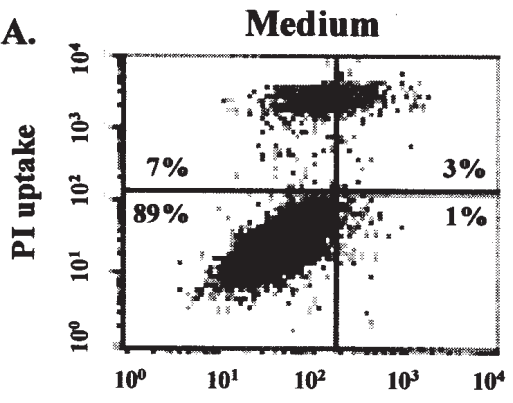

Annexin $\mathrm{V}$ binding

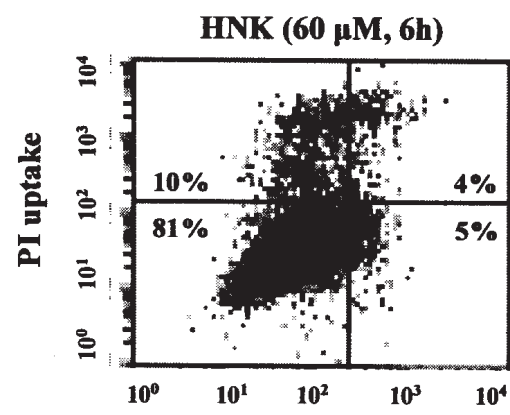

Annexin $\mathrm{V}$ binding

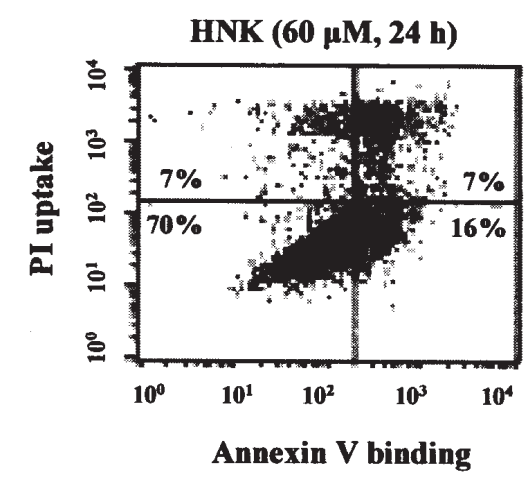

C.

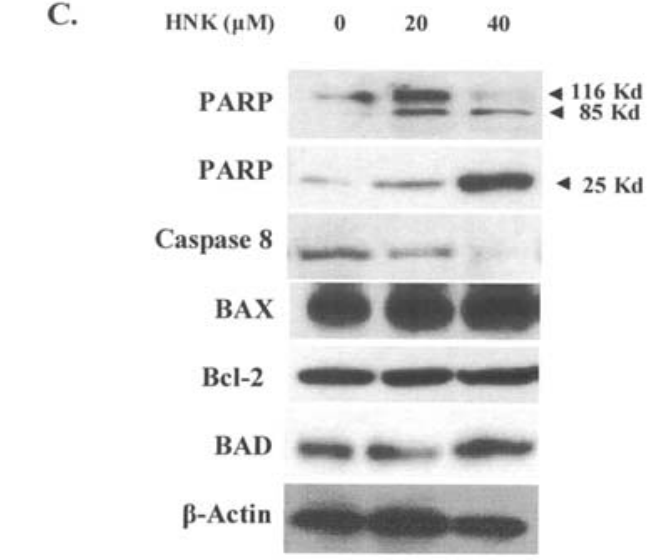

B.

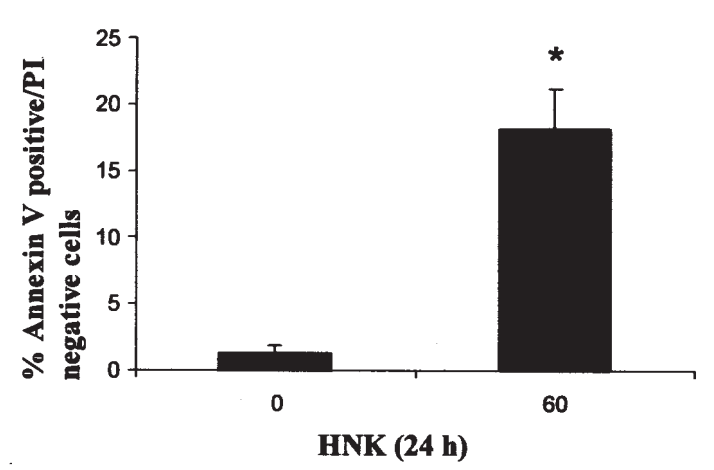

Figure 5. HNK induces apoptosis in breast cancer cells. (A) MCF-7 cells were treated with HNK (60 $\mu \mathrm{M})$ for the indicated time. Following treatment, the cells were harvested and stained for PI and annexin V, as described in Materials and methods. Representative results are shown. (B) Results of three independent experiments (HNK $60 \mu \mathrm{M}, 24 \mathrm{~h}$ ) are shown. ${ }^{*} \mathrm{P}<0.05$. (C) MCF-7 cells were treated with HNK (20 or $\left.40 \mu \mathrm{M}, 24 \mathrm{~h}\right)$, lysed and analyzed by Western blotting for the expression of apoptosis-related proteins. 
A.

\section{MDA-MB-231}

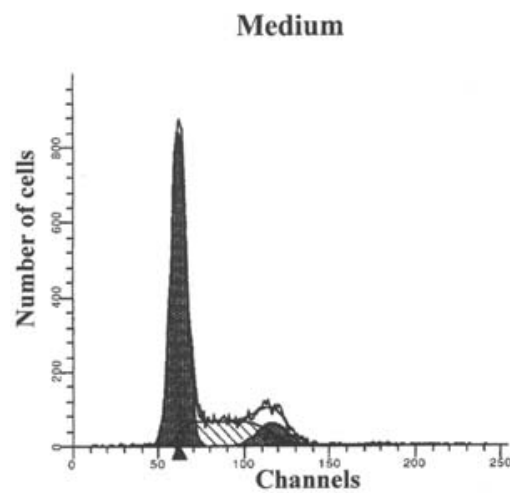

C.

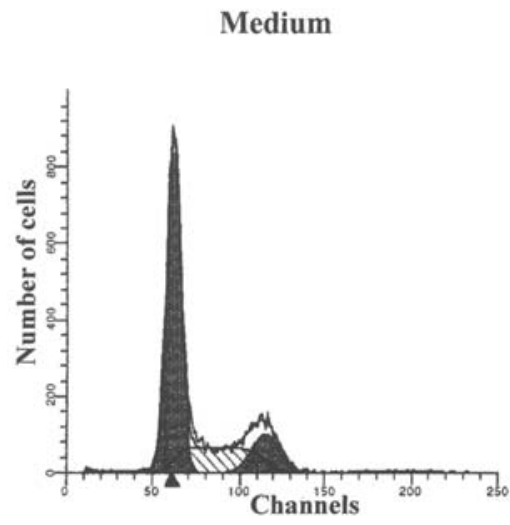

E.
HNK $(30 \mu \mathrm{M}, 24 \mathrm{~h})$

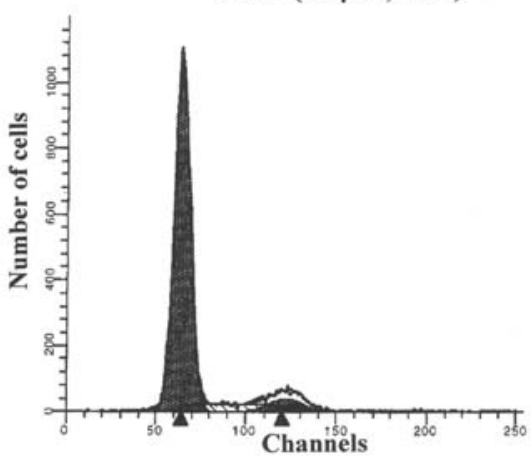

B.

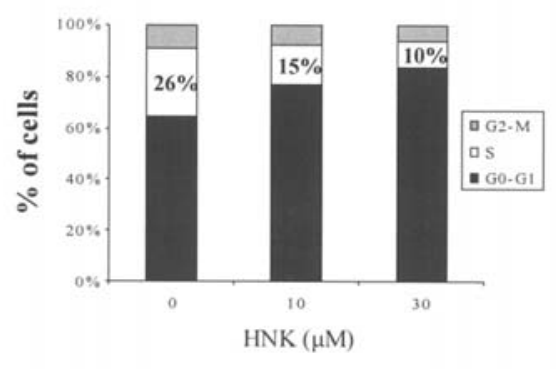

MCF-7

$\operatorname{HNK}(30 \mu \mathrm{M}, 24 \mathrm{~h})$

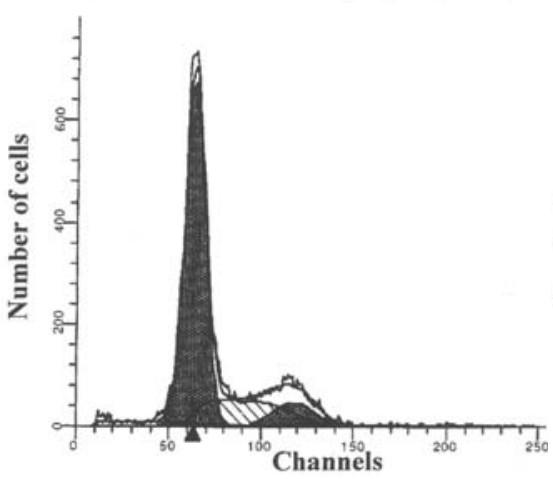

F.
D.

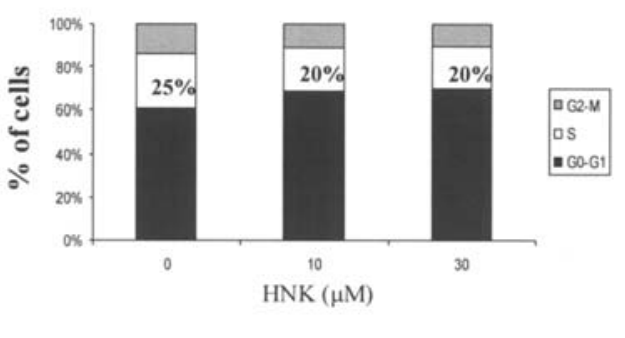

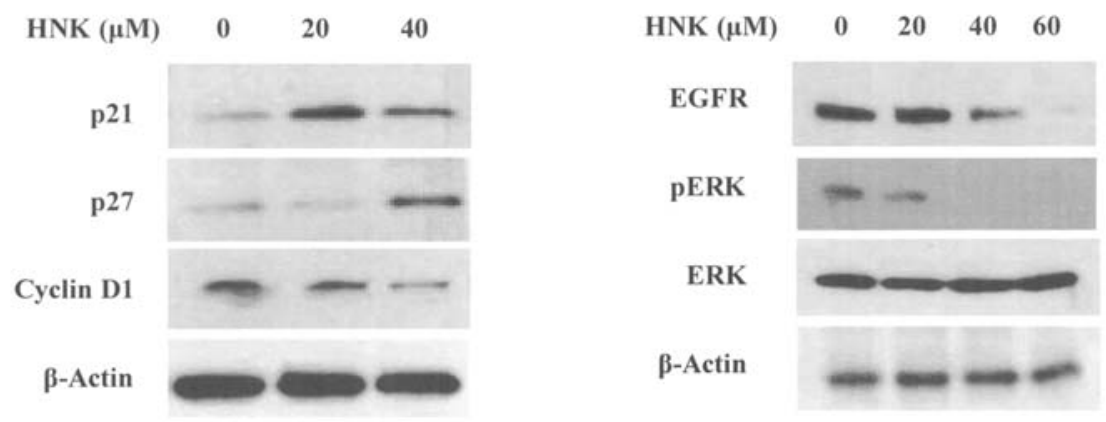

Figure 6. HNK slows cell cycle in breast cancer cells. (A) MDA-MB-231 cells were treated with HNK $(30 \mu \mathrm{M}, 24 \mathrm{~h})$ and analyzed for cell cycle using PI staining, as described in Materials and methods. (B) The results of three independent experiments are shown. P $>0.05$ for the percentage of cells in S-phase in the control compared to those treated with $30 \mu \mathrm{M}$ HNK. (C) MCF-7 cells were treated with HNK (30 $\mu \mathrm{M}, 24 \mathrm{~h})$ and analyzed for cell cycle using PI staining, as described in Materials and methods. (D) Results of three independent experiments are shown. (E) MDA-MB-231 cells were treated with HNK (20, 40 or $60 \mu \mathrm{M}$, for $24 \mathrm{~h}$ ), lysed and analyzed by Western blotting for the expression of cell cycle related proteins. (F) MDA-MB-231 cells were treated with HNK (20, 40 or $60 \mu \mathrm{M}$, for $24 \mathrm{~h}$ ), lysed and analyzed by Western blotting for the expression of EGFR and total and phosphorylated ERK2, as well as B-actin.

to control, as analyzed by densitometry), but no significant changes in BCL-2 or BAD levels were observed. Only partial inhibition of apoptosis was observed following pretreatment with z-VAD-fmk (data not shown).

HNK slows cell cycle in breast cancer cell lines. The effects of HNK (10 or $30 \mu \mathrm{M} \mathrm{HNK}$ for $24 \mathrm{~h}$ ) on cell cycle were evaluated in MCF-7 and MDA-MB-231 cells. These doses of HNK are less than the LC50 for both cell lines. HNK at $10 \mu \mathrm{M}$ and $30 \mu \mathrm{M}$ significantly reduced the number of MDAMB-231 cells in S-phase compared to control cells (15\% and $10 \%$ versus $26 \%$, respectively, $\mathrm{P}<0.005$, Fig. $6 \mathrm{~A}$ and B). A less pronounced effect was observed for MCF-7 cells with $26 \%$, $20 \%$ and $20 \%$ of the cells in S-phase in the control, $10 \mu \mathrm{M}$ 
or $30 \mu \mathrm{M}$ groups, respectively (Fig. 6C and D). Expression of proteins involved in G1 cell-cycle regulation (32) was examined in MDA-MB-231 cells using Western analysis. HNK treatment $(20,40$ and $60 \mu \mathrm{M}$ HNK for $24 \mathrm{~h})$ reduced the levels of cyclin D1, and upregulated expression of the cyclin-dependent kinase inhibitors, p27 and p21 (Fig. 6E).

HNK inhibits growth signaling pathways. In endothelial cells, HNK inhibits the activity of the KDR receptor and its downstream signaling cascades, the MAPK and the PI3K pathways (19). In breast cancer, both pathways are activated through the epidermal growth factor receptor (EGFR) (33). This EGFR-mediated signaling is especially important in ERnegative breast cancer; and its inhibition slows the growth of ER-negative cells, such as MDA-MB-231 (33-35). We analyzed the effects of HNK on the expression of the EGFR and the activity of the MAPK and the PI3K pathways in the MDA-MB-231 cells and found reduced expression of EGFR and reduced phosphorylation of ERK2 (extracellular signalregulated kinase 2) following exposure to HNK (Fig. 6F). No significant change in AKT phosphorylation was observed (data not shown).

\section{Discussion}

In this study we show, for the first time, in vitro and in vivo activity of HNK against breast cancer cells. Growth inhibition was observed in all breast cancer cell lines tested, regardless of their HR, HER2 or p53 status, but it was not observed for glioblastoma multiforme cells. Similar to other tumors (7-20), our studies revealed LC50 at a range of 29-50 $\mu \mathrm{M}$ for breast cancer cell lines. Of interest, the lowest LC50 values were observed for the HR-negative, p53-mutated MDAMB-231 and SK-BR-3 cell lines. The SK-BR-3 cell line also expresses high levels of HER2. This observation is of potential therapeutic importance, as HR-negative breast cancers have a shortened survival compared with HR-positive breast cancers. Moreover, chemotherapy is currently the only therapeutic option for HR-negative, HER2-negative (triple negative) breast tumors (27). Importantly, the doses of HNK in this study do not affect the growth of normal mononuclear cells, fibroblasts, lymphocytes $(11,13,19)$ or glioblastoma cells (present study). Thus, HNK effect seems to be cell- and tumor-type specific.

We and others observed in vivo activity of HNK against angiosarcomas (19), colon (13) and breast cancers (present study) following i.p. administration of $100-120 \mathrm{mg} / \mathrm{kg}$. Previous pharmacological studies in mice and rats revealed that HNK is readily absorbed following oral, i.v. or i.p. administration, its serum half-life is $>5 \mathrm{~h}$, and its plasma concentration is similar to the concentration needed to induce in vitro cytotoxicity against breast cancer (36-39). Moreover, HNK administration was well tolerated and no weight loss or other major side effects were observed in this and in previous other animal studies $(13,19,37)$. Thus, HNK administration, at effective doses to treat breast cancer, seems to be safe and feasible.

In myeloma, HNK enhanced the activity of various cytotoxic drugs; and in B-CLL, it enhanced the activity of bortezomib $(10,11)$. We observed enhancement of activity of 4-HT and doxorubicin and paclitaxel by HNK, and using the additive model $(25,26,40,41)$, identified synergistic activity for the combination of HNK and SAHA. SAHA is an HDAC inhibitor, which has been shown to be active against breast cancer cells, through induction of cell cycle arrest, apoptosis and differentiation $(29,42)$. Recent data suggest that, independent of its activity as an HDAC inhibitor, SAHA can also activate caspases and inhibit AKT phosphorylation $(42,43)$. Thus, SAHA may share common mechanisms of action with HNK.

We identified two different effects of HNK on breast cancer cells: cell cycle inhibition observed at lower doses of $\mathrm{HNK}$, and induction of apoptosis observed at higher doses of the compound. Similar to previous reports, we observed both caspase-dependent and -independent apoptosis following HNK administration $(10,11)$. HNK stimulated cleavage of PARP and upregulation of expression of BAX, but did not affect levels of BAD or Bcl-2. Upregulation of BAX was also observed in B-CLL following HNK treatment, while upregulation of Bad was observed in colon and lung cancers $(10,11,14,15)$. Thus, HNK may be involved in the activation of different members of the Bcl-2 family in different tumors.

Our studies demonstrate that HNK slowed the cell cycle; and its administration was associated with downregulation of cyclin D1 and upregulation of the cell cycle inhibitors p27 and p21. Cell cycle inhibition was observed at HNK doses that were lower than the LC50 and were closer to the expected plasma levels following i.p. HNK administration $(13,38)$. Indeed in our xenograft model, we observed arrest of tumor growth but not tumor regression. Thus, the major in vivo effects of HNK could possibly be attributed to inhibition of growth modulating pathways, rather than induction of apoptosis.

We observed HNK-induced downregulation of the EGFR and inhibition of its downstream pathway, the MAPK cascade. Overexpression and impaired downregulation of the EGFR play an important role in cancer development $(44,45)$; and cancer therapy can induce its downregulation through induction of ubiquitination or activation of caspases (46-48). Our findings suggest downregulation of the EGFR as a novel mechanism of action for HNK. In myeloma and angiosarcoma, the MAPK pathway was also inhibited by HNK, but the effects of HNK on the expression of the upstream receptors have not been determined $(11,19)$. As we did not observe increased ubiquitination of the EGFR (data not shown), other mechanisms, such as caspase activation, may be involved in HNK-induced EGFR downregulation.

In conclusion, we have shown that HNK induces apoptosis and slows the cell cycle of breast cancer cells, and it is systematically active against breast cancer in vivo. Moreover, HNK was well tolerated by the animals in therapeutically beneficial doses. These results suggest that HNK, either alone or in combination with other drugs, may be an effective therapeutic agent in the treatment of breast cancer.

\section{Acknowledgements}

This study was supported in part by the Inger Fund, Alec Borden Trust, Rountree Trust and the Mary Barry Foundation and by grants from the Women's Cancer Research Institute, 
Samuel Oschin Comprehensive Cancer Institute at CedarsSinai Medical Center. H.P.K is a member of the Molecular Biology Institute and Jonsson Comprehensive Cancer Center at UCLA, and holds the endowed Mark Goodson Chair of Oncology Research at Cedars-Sinai Medical Center/UCLA School of Medicine. I.W. is the Mary Barry Medical Bridges Foundation Fellow.

\section{References}

1. Tsai TH and Chen CF: Identification and determination of honokiol and magnolol from Magnolis officinalis by highperformance liquid chromatography with photodiode-array UV detection. J Chromatogr 598: 143-146, 1992.

2. Esumi T, Makado G, Zhai H, Shimizu Y, Mitsumoto Y and Fukuyama Y: Efficient synthesis and structure-activity relationship of honokiol, a neurotrophic biphenyl-type neolignan. Bioorg Med Chem Lett 14: 2621-2625, 2004.

3. Teng CM, Chen CC, Ko FN, et al: Two antiplatelet agents from Magnolia officinalis. Thromb Res 50: 757-765, 1988.

4. Clark AM, El-Feraly FS and Li WS: Antimicrobial activity of phenolic constituents of Magnolia grandiflora L. J Pharm Sci 70: 951-952, 1981

5. Liou KT, Shen YC, Chen CF, Tsao CM and Tsai SK: Honokiol protects rat brain from focal cerebral ischemia-reperfusion injury by inhibiting neutrophil infiltration and reactive oxygen species production. Brain Res 992: 159-166, 2003.

6. Watanabe K, Watanabe H, Goto Y, Yamaguchi M, Yamamoto N and Hagino K: Pharmacological properties of magnolol and honokiol extracted from Magnolia officinalis: central depressant effects. Planta Med 49: 103-108, 1983.

7. Hirano T, Gotoh M and Oka K: Natural flavonoids and lignans are potent cytostatic agents against human leukemic HL-60 cells. Life Sci 55: 1061-1069, 1994.

8. Fong WF, Tse AK, Poon KH and Wang C: Magnolol and honokiol enhance HL-60 human leukemia cell differentiation induced by 1,25-dihydroxyvitamin D3 and retinoic acid. Int J Biochem Cell Biol 37: 427-441, 2005.

9. Tse AK, Wan CK, Shen XL, Yang M and Fong WF: Honokiol inhibits TNF-alpha-stimulated NF-kappaB activation and NFkappaB-regulated gene expression through suppression of IKK activation. Biochem Pharmacol 70: 1443-1457, 2005.

10. Battle TE, Arbiser J and Frank DA: The natural product honokiol induces caspase-dependent apoptosis in B-cell chronic lymphocytic leukemia (B-CLL) cells. Blood 106: 690-697, 2005.

11. Ishitsuka K, Hideshima T, Hamasaki M, Raje N, Kumar S, Hideshima $\mathrm{H}$, et al: Honokiol overcomes conventional drug resistance in human multiple myeloma by induction of caspasedependent and -independent apoptosis. Blood 106: 1794-1800, 2005.

12. Hibasami H, Achiwa Y, Katsuzaki H, Imai K, Yoshioka K, Nakanishi K, et al: Honokiol induces apoptosis in human lymphoid leukemia Molt 4B cells. Int J Mol Med 2: 671-673, 1998.

13. Chen F, Wang T, Wu YF, Gu Y, Xu XL, Zheng S, et al: Honokiol: a potent chemotherapy candidate for human colorectal carcinoma. World J Gastroenterol 10: 3459-3463, 2004.

14. Wang T, Chen F, Chen Z, Wu YF, Xu XL, Zheng S, et al: Honokiol induces apoptosis through p53-independent pathway in human colorectal cell line RKO. World J Gastroenterol 10: 2205-2208, 2004.

15. Yang SE, Hsieh MT, Tsai TH and Hsu SL: Down-modulation of $\mathrm{Bcl}-\mathrm{XL}$, release of cytochrome $\mathrm{C}$ and sequential activation of caspases during honokiol-induced apoptosis in human squamous lung cancer CH27 cells. Biochem Pharmacol 63: 1641-1651, 2002.

16. Kong ZL, Tzeng SC and Liu YC: Cytotoxic neolignans: an SAR study. Bioorg Med Chem Lett 15: 163-166, 2005.

17. Konoshima T, Kozuka M, Tokuda H, Nishino H, Iwashima A, Haruna M, et al: Studies on inhibitors of skin tumor promotion, IX. Neolignans from Magnolia officinalis. J Nat Prod 54: 816-822, 1991.

18. Xu D, Lu Q and Hu X: Down-regulation of P-glycoprotein expression in MDR breast cancer cell MCF-7/ADR by honokiol. Cancer Lett (Epub ahead of print), 2006.
19. Bai X, Cerimele F, Ushio-Fukai M, Waqas M, Campbell PM, Govindarajan B, et al: Honokiol, a small molecular weight natural product, inhibits angiogenesis in vitro and tumor growth in vivo. J Biol Chem 278: 35501-35507, 2003.

20. Park EJ, Zhao YZ, Kim YH, Lee BH and Sohn DH: Honokiol induces apoptosis via cytochrome $\mathrm{c}$ release and caspase activation in activated rat hepatic stellate cells in vitro. Planta Med 71: $82-84,2005$.

21. Zhai H, Nakade K, Mitsumoto Y and Fukuyama Y: Honokiol and magnolol induce $\mathrm{Ca} 2{ }^{+}$mobilization in rat cortical neurons and human neuroblastoma SH-SY5Y cells. Eur J Pharmacol 474: 199-204, 2003

22. Lin SY, Liu JD, Chang HC, Yeh SD, Lin CH and Lee WS: Magnolol suppresses proliferation of cultured human colon and liver cancer cells by inhibiting DNA synthesis and activating apoptosis. J Cell Biochem 84: 532-544, 2002.

23. Lacey JV Jr, Devesa SS and Brinton LA: Recent trends in breast cancer incidence and mortality. Environ Mol Mutagen 39: 82-88, 2002.

24. Bernard-Marty C, Cardoso F and Piccart MJ: Facts and controversies in systemic treatment of metastatic breast cancer. Oncologist 9: 617-632, 2004.

25. Valeriote $\mathrm{F}$ and Lin H: Synergistic interaction of anticancer agents: a cellular perspective. Cancer Chemother Rep 59: 895-900, 1975.

26. Jonsson E, Fridborg H, Nygren P and Larsson R: Synergistic interactions of combinations of topotecan with standard drugs in primary cultures of human tumor cells from patients. Eur J Clin Pharmacol 54: 514, 1998.

27. Lacroix M and Leclercq G: Relevance of breast cancer cell lines as models for breast tumours: an update. Breast Cancer Res Treat 83: 249-289, 2004

28. Sutherland RL, Hall RE and Taylor IW: Cell proliferation kinetics of MCF-7 human mammary carcinoma cells in culture and effects of tamoxifen on exponentially growing and plateauphase cells. Cancer Res 43: 3998-4006, 1983.

29. Munster PN, Troso-Sandoval T, Rosen N, Rifkind R, Marks PA and Richon VM: The histone deacetylase inhibitor suberoylanilide hydroxamic acid induces differentiation of human breast cancer cells. Cancer Res 61: 8492-8497, 2001

30. Huang L and Pardee AB: Suberoylanilide hydroxamic acid as a potential therapeutic agent for human breast cancer treatment. Mol Med 6: 849-866, 2000

31. Simoes-Wust AP, Schurpf T, Hall J, Stahel RA and Zangemeister-Wittke U: Bcl-2/bcl-xL bispecific antisense treatment sensitizes breast carcinoma cells to doxorubicin, paclitaxel and cyclophosphamide. Breast Cancer Res Treat 76: 157-166, 2002.

32. Massague J: G1 cell-cycle control and cancer. Nature 432: 298-306, 2004.

33. Atalay G, Cardoso F, Awada A and Piccart MJ: Novel therapeutic strategies targeting the epidermal growth factor receptor (EGFR) family and its downstream effectors in breast cancer. Ann Oncol 14: 1346-1363, 2003.

34. Davidson NE, Gelmann EP, Lippman ME and Dickson RB: Epidermal growth factor receptor gene expression in estrogen receptor-positive and negative human breast cancer cell lines. Mol Endocrinol 1: 216-223, 1987.

35. Anderson NG, Ahmad T, Chan K, Dobson R and Bundred NJ: ZD1839 (Iressa), a novel epidermal growth factor receptor (EGFR) tyrosine kinase inhibitor, potently inhibits the growth of EGFR-positive cancer cell lines with or without erbB2 overexpression. Int J Cancer 94: 774-782, 2001.

36. Maruyama $Y$, Kuribara $H$, Morita $M$, Yuzurihara $M$ and Weintraub ST: Identification of magnolol and honokiol as anxiolytic agents in extracts of saiboku-to, an oriental herbal medicine. J Nat Prod 61: 135-138, 1998.

37. Kuribara H, Kishi E, Hattori N, Okada M and Maruyama Y: The anxiolytic effect of two oriental herbal drugs in Japan attributed to honokiol from magnolia bark. J Pharm Pharmacol 52: $1425-1429,2000$

38. Tsai TH, Chou CJ, Cheng FC and Chen CF: Pharmacokinetics of honokiol after intravenous administration in rats assessed using high-performance liquid chromatography. J Chromatogr B Biomed Appl 655: 41-45, 1994.

39. Kuribara H, Kishi E, Kimura M, Weintraub ST and Maruyama Y: Comparative assessment of the anxiolytic-like activities of honokiol and derivatives. Pharmacol Biochem Behav 67: 597-601, 2000.

40. Rothman KJ: The estimation of synergy or antagonism. Am J Epidemiol 103: 506-511, 1976. 
41. Etminan M: Quantifying the interaction between angiotensinconverting enzyme inhibitors and aspirin: are we using the right method? Pharmacotherapy 21: 1247-1249, 2001.

42. Mei S, Ho AD and Mahlknecht U: Role of histone deacetylase inhibitors in the treatment of cancer. Int J Oncol 25: 1509-1519, 2004.

43. Chen CS, Weng SC, Tseng PH, Lin HP and Chen CS: Histone acetylation-independent effect of histone deacetylase inhibitors on Akt through the reshuffling of protein phosphatase 1 complexes. J Biol Chem 280: 38879-38887, 2005.

44. Bache KG, Slagsvold T and Stenmark H: Defective downregulation of receptor tyrosine kinases in cancer. EMBO J 23: 2707-2712, 2004.
45. Marmor MD and Yarden Y: Role of protein ubiquitylation in regulating endocytosis of receptor tyrosine kinases. Oncogene 23: 2057-2070, 2004.

46. Citri A, Alroy I, Lavi S, Rubin C, Xu W, Grammatikakis N et al: Drug-induced ubiquitylation and degradation of ErbB receptor tyrosine kinases: implications for cancer therapy. EMBO J 21: 2407-2417, 2002.

47. He YY, Huang JL and Chignell CF: Ceavage of epidermal growth factor receptor by caspase during apoptosis is independent of its internalization. Oncogene 25: 1521-1531, 2006.

48. Bae SS, Choi JH, Oh YS, Perry DK, Ryu SH and Suh PG: Proteolytic cleavage of epidermal growth factor receptor by caspases. FEBS Lett 491: 16-20, 2001. 